\title{
Formulation Development and Evaluation of Fast Disintegrating Tablet of Cetirizine Hydrochloride: A Novel Drug Delivery for Pediatrics and Geriatrics
}

\author{
Deepak Sharma, ${ }^{1}$ Mankaran Singh, ${ }^{2}$ Dinesh Kumar, ${ }^{3}$ and Gurmeet Singh ${ }^{4}$ \\ ${ }^{1}$ Department of Pharmaceutics, Rayat Bahra Institute of Pharmacy, Hoshiarpur-146001, Punjab, India \\ ${ }^{2}$ Quantum Solutions, Chandigarh, Punjab, India \\ ${ }^{3}$ CSIR Institute of Microbial Technology, Chandigarh, Punjab, India \\ ${ }^{4}$ CT Institute of Pharmaceutical Sciences, Jalandhar-144020, Punjab, India
}

Correspondence should be addressed to Deepak Sharma; deepakpharmacist89@yahoo.com

Received 16 November 2013; Revised 4 January 2014; Accepted 6 January 2014; Published 18 February 2014

Academic Editor: Jae Hyung Park

Copyright (C) 2014 Deepak Sharma et al. This is an open access article distributed under the Creative Commons Attribution License, which permits unrestricted use, distribution, and reproduction in any medium, provided the original work is properly cited.

\begin{abstract}
Recent developments in fast disintegrating tablets have brought convenience in dosing to pediatric and elderly patients who have trouble in swallowing tablets. The objective of the present study was to prepare the fast disintegrating tablet of Cetirizine Hydrochloride for allergic and respiratory disorders. As precision of dosing and patient's compliance become important prerequisite for a long-term treatment, there is a need to develop a formulation for this drug which overcomes problems such as difficulty in swallowing, inconvenience in administration while travelling, and patient's acceptability. Hence, the present investigation was undertaken with a view to develop a fast disintegrating tablet of Cetirizine Hydrochloride which offers a new range of products having desired characteristics and intended benefits. Superdisintegrants such as Sodium Starch Glycolate were optimized. Different binders were optimized along with optimized superdisintegrant concentration. The tablets were prepared by direct compression technique. The tablets were evaluated for hardness, friability, weight variation, wetting time, disintegration time and uniformity of content. Optimized formulation was evaluated by in vitro dissolution test, drug excipient compatibility and accelerated stability study. It was concluded that fast disintegrating tablets of Cetirizine Hydrochloride were formulated successfully with desired characteristics which disintegrated rapidly, provide rapid onset of action, and enhance the patient convenience and compliance.
\end{abstract}

\section{Introduction}

In spite of the increased focus and interest generated in the area of controlled release and targeted drug delivery system in recent years, tablet dosage forms that are intended to be swallowed whole, disintegrate, and release their medicaments rapidly in the gastrointestinal tract still remain the formulation of choice from both a manufacturing as well as a patient acceptability point of view. Thus, a drug given in the form of a tablet must undergo dissolution before being absorbed and eventually transported into systemic circulation [1]. Difficulties with and resistance to tablettaking are most common in all patient groups and can exacerbate compliance problems and undermine treatment efficacy. Physical problems with swallowing (dysphasia) can occur at any age but are particularly prevalent in geriatric, pediatric, and psychiatric patients. Nonetheless, oral dosing remains the preferred mode of administration for many types of medication due to its simplicity, versatility, convenience, and patient acceptability [2]. By considering the above points, patient convenience and compliance oriented research has resulted in bringing out safer and newer drug delivery systems; one of such approaches is fast disintegrating drug delivery system [3]. Fast disintegrating drug delivery systems (FDDDS) are a new generation of formulations which combine the advantages of both liquid and conventional tablet formulations and, at the same time, offer added advantages over both traditional dosage forms. They provide the convenience of a tablet formulation and also allow the ease of swallowing provided by a liquid formulation. FDDDS 
offer the luxury of much more accurate dosing than the primary alternative, oral liquids [4]. Recent advances in novel drug delivery systems (NDDS) aim at enhancing the safety of a drug molecule while maintaining its therapeutic efficacy so as to achieve better patient compliance [5]. US Food and Drug Administration Center for Drug Evaluation and Research (CDER) defines, in the "Orange Book," a FDT as "a solid dosage form containing medicinal substances, which disintegrates rapidly, usually within a matter of seconds, when placed upon the tongue". European Pharmacopoeia described FDTs as "uncoated tablets intended to be placed in the mouth where they disperse rapidly before being swallowed" and as tablets which should disintegrate within 3 minutes [6]. Fast disintegrating tablets (FDT) are also known as fast dissolving, mouth dissolving, rapid-dissolving, quick disintegrating, orally disintegrating, rapimelt, fast melt, orodispersible, meltin-mouth, quick dissolving, porous tablets, and EFVDAS (Effervescent Drug Absorption System) [7]. The bioavailability of drugs may be increased due to absorption of drug in oral cavity and also due to pregastric absorption of saliva containing dispersed drugs that pass down into the stomach. Moreover, the amount of drug that is subjected to the first pass metabolism is reduced as compared to standard tablet [8]. Formulation of the drug chosen for the treatment of allergic cough and other respiratory disorders is available in market in conventional tablet and liquid dosage forms. Liquid dosage forms are having their own limitation from stability and dose measurement perspectives. Tablets to be swallowed are resisted by pediatric patients and patient compliance is an issue with such dosage forms. Hence they do not comply with the prescription, which results in high incidence of noncompliance and ineffective therapy. The benefits, in terms of patient compliance, rapid onset of action, increased bioavailability, and good stability make fast disintegrating tablets popular as a dosage form of choice in the current market [9]. Cetirizine Hydrochloride is the active metabolite of the piperazine $\mathrm{H}_{1}$-receptor antagonist Hydroxyzine. It is a nonsedative second generation antihistamine drug used in the treatment of seasonal allergic rhinitis, perennial allergic rhinitis, chronic urticaria, and atopic dermatitis and also used as adjuvant in seasonal asthma and allergic cough. Cetirizine inhibits the release of histamine and of cytotoxic mediators from platelets, as well as eosinophil chemotaxis during the secondary phase of allergic response. Due to sore throat conditions, the patient experiences difficulty in swallowing a tablet type of dosage form. Thus, fast disintegrating tablets would serve as an ideal dosage form pediatric patients who find it difficult to swallow the conventional tablets and capsules [10]. Hence an attempt was made for preparation of fast disintegrating tablet of Cetirizine Hydrochloride with an aim of improving/enhancing patient convenience and compliance, reducing the lag time and providing faster onset of action to relieve the allergic and respiratory disorders immediately.

\section{Materials and Methods}

2.1. Materials. Cetirizine Hydrochloride was received as gift sample from Trojan Pharma, Baddi, India. Microcrystalline
TABLE 1: Formula for 1 tablet $(200 \mathrm{mg}$ ) of different concentration of Sodium Starch Glycolate (data in $\mathrm{mg}$ ).

\begin{tabular}{|c|c|c|c|c|c|c|c|}
\hline $\begin{array}{l}\text { Sr. } \\
\text { number }\end{array}$ & Ingredients & $\mathrm{F} 1$ & $\mathrm{~F} 2$ & F3 & $\mathrm{F} 4$ & F5 & F6 \\
\hline 1 & $\begin{array}{c}\text { Cetirizine } \\
\text { Hydrochloride }\end{array}$ & 5 & 5 & 5 & 5 & 5 & 5 \\
\hline 2 & $\begin{array}{l}\text { Sodium Starch } \\
\text { Glycolate }\end{array}$ & $\begin{array}{c}2 \\
(1 \%)\end{array}$ & $\begin{array}{c}4 \\
(2 \%)\end{array}$ & $\begin{array}{c}8 \\
(4 \%)\end{array}$ & $\begin{array}{c}12 \\
(6 \%)\end{array}$ & $\begin{array}{c}16 \\
(8 \%)\end{array}$ & $\begin{array}{c}20 \\
(10 \%)\end{array}$ \\
\hline 3 & $\begin{array}{l}\text { Polyvinylpyrrolidone } \\
\text { K-30 }\end{array}$ & 4 & 4 & 4 & 4 & 4 & 4 \\
\hline 4 & Magnesium Stearate & 3 & 3 & 3 & 3 & 3 & 3 \\
\hline 5 & Talc & 3 & 3 & 3 & 3 & 3 & 3 \\
\hline 6 & Sodium Saccharin & 5 & 5 & 5 & 5 & 5 & 5 \\
\hline 7 & Mannitol & 178 & 176 & 172 & 168 & 164 & 160 \\
\hline
\end{tabular}

Cellulose (Avicel PH-102) was obtained as gift sample from NB Entrepreneurs, Nagpur, India. Sodium Starch Glycolate (Primogel, Explotab) and directly compressible Mannitol (DMannitol) were purchased from Qualikems Fine Chem Pvt. Ltd. Sodium Srearyl Fumarate was Purchased from Himedia. Sodium Saccharin was purchased from Loba Chemie, Mumbai, and Talc from Nice Chemicals Private Limited, Hyderabad, India. All other chemicals and reagents which were of analytical grade were used.

\subsection{Methods}

2.2.1. Selection of Excipients and Optimization of Their Concentration. The most important parameter that needs to be optimized in the development of fast disintegrating tablets is the disintegration time. Fast disintegrating tablets were prepared firstly using different excipients (binders and superdisintegrants) and then evaluated for various parameters like friability, hardness, and disintegration time to select the best combination for formulation of fast disintegrating tablets. The combination with the lowest disintegration time, optimum hardness, and friability was selected for further study.

Optimization of Superdisintegrant Sodium Starch Glycolate (Primogel, Explotab). For tablets and capsules which require rapid disintegration, the inclusion of the right superdisintegrant and in its optimum concentration is a prerequisite for optimal bioavailability. Superdisintegrants decrease disintegration time which in turn enhances drug dissolution rate. Thus, the proper choice of superdisintegrant its consistency of performance are of critical importance to the formulation of rapidly disintegrating dosage forms.

Formulation F1-F6 was prepared to study the effect of type and concentration of superdisintegrants in Table 1. Tablets were prepared by direct compression technique. Weighed quantity of Cetirizine Hydrochloride with different concentration of superdisintegrant along with excipients was mixed in geometric progression in a dry and clean mortar. Then the blend was passed through sieve number 60 for direct compression. The powder blend was then compressed into 
TABle 2: Formula for 1 tablet $(200 \mathrm{mg}$ ) for the optimization of Polyvinylpyrrolidone K-30 or Microcrystalline Cellulose with optimized concentration of Sodium Starch Glycolate.

\begin{tabular}{|c|c|c|c|c|c|c|c|c|}
\hline \multirow[b]{2}{*}{$\begin{array}{l}\text { Formula } \\
\text { number }\end{array}$} & \multicolumn{8}{|c|}{ Contents } \\
\hline & $\begin{array}{l}\text { Cetirizine } \\
\text { Hydrochloride } \\
(\mathrm{mg})\end{array}$ & SSG (mg) & PVP K-30 (mg) & MCC (mg) & $\begin{array}{l}\text { Sodium Stearyl } \\
\text { Fumarate (mg) }\end{array}$ & Talc (mg) & $\begin{array}{l}\text { Sodium } \\
\text { Saccharin } \\
(\mathrm{mg})\end{array}$ & Mannitol (mg) \\
\hline F1 & 5 & 8 & 2 & - & 2 & 2 & 5 & 176 \\
\hline F2 & 5 & 8 & 4 & - & 2 & 2 & 5 & 174 \\
\hline F3 & 5 & 8 & 6 & - & 2 & 2 & 5 & 172 \\
\hline $\mathrm{F} 4$ & 5 & 8 & 8 & - & 2 & 2 & 5 & 170 \\
\hline F5 & 5 & 8 & 10 & - & 2 & 2 & 5 & 168 \\
\hline F6 & 5 & 8 & 12 & - & 2 & 2 & 5 & 166 \\
\hline F7 & 5 & 8 & 14 & & 2 & 2 & 5 & 164 \\
\hline F8 & 5 & 8 & - & 2 & 2 & 2 & 5 & 176 \\
\hline F9 & 5 & 8 & - & 4 & 2 & 2 & 5 & 174 \\
\hline F10 & 5 & 8 & - & 6 & 2 & 2 & 5 & 172 \\
\hline F11 & 5 & 8 & - & 8 & 2 & 2 & 5 & 170 \\
\hline F12 & 5 & 8 & - & 10 & 2 & 2 & 5 & 168 \\
\hline F13 & 5 & 8 & - & 12 & 2 & 2 & 5 & 166 \\
\hline F14 & 5 & 8 & - & 14 & 2 & 2 & 5 & 164 \\
\hline
\end{tabular}

TABLE 3: Formula of Cetirizine Hydrochloride FDT prepared by direct compression method (data in $\mathrm{mg}$ ).

\begin{tabular}{lccc}
\hline $\begin{array}{l}\text { Sr. } \\
\text { number }\end{array}$ & Ingredients & $\begin{array}{c}\text { Formula for 1 } \\
\text { tablet } \\
(200 \mathrm{mg})\end{array}$ & $\begin{array}{c}\text { Formula for } \\
\text { 110 tablets } \\
(200 \mathrm{mg})\end{array}$ \\
\hline 1 & Cetirizine Hydrochloride & 5 & 550 \\
2 & Sodium Starch Glycolate & 8 & 880 \\
3 & Microcrystalline Cellulose & 2 & 220 \\
4 & Sodium Stearyl Fumarate & 4 & 440 \\
5 & Talc & 2 & 220 \\
6 & Sodium Saccharin & 8 & 880 \\
7 & Mint flavor & 8 & 880 \\
8 & Mannitol & 163 & 17930 \\
\hline
\end{tabular}

TABle 4: Weight variation specification as per Indian Pharmacopoeia (IP).

\begin{tabular}{lc}
\hline Average weight of tablet & \% deviation \\
\hline $80 \mathrm{mg}$ or less & \pm 10 \\
More than $80 \mathrm{mg}$ but less than $250 \mathrm{mg}$ & \pm 7.5 \\
$250 \mathrm{mg}$ or more & \pm 5 \\
\hline
\end{tabular}

tablets using $8 \mathrm{~mm}$ punch in multi punch tablet compression machine (Dhiman Industries, India).

Optimization of Polyvinylpyrrolidone (PVP K-30) or Microcrystalline Cellulose (Avicel PH-102) as Binder along with Optimized Concentration of Superdisintegrant. Tablets were prepared by direct compression technique. The composition of fast disintegrating tablet is shown in Table 2. Weighed quantity of Cetirizine Hydrochloride with optimized concentration of Sodium Starch Glycolate along with different concentration of binders (PVP K-30, MCC) along with excipients was mixed in geometric progression in a dry and clean mortar. Then the blend was passed through sieve number 60 for direct compression. The powder blend was then compressed into tablets using $8 \mathrm{~mm}$ punch in multi punch tablet compression machine (Dhiman Industries, India).

2.3. Final Formulation of Cetirizine Hydrochloride Fast Disintegrating Tablets by Direct Compression Method. Fast disintegrating tablets of Cetirizine Hydrochloride were prepared by direct compression method according to the formula given in Table 3. Weighed quantities of Cetirizine Hydrochloride along with optimized concentration of superdisintegrant and binder along with excipients were mixed in geometric progression in a dry and clean mortar. Then the blend was passed through sieve no. 60 for direct compression. The powder blend was then compressed into tablets using $8 \mathrm{~mm}$ punch in multi punch tablet compression machine. These fabricated tablets were evaluated.

\subsection{Evaluation Parameters}

2.4.1. Weight Variation. Twenty tablets were selected, weighed on digital weighting balance (Ohaus, USA) and average weight was determined. Then individual tablets were weighed and the individual weight was compared with an average weight as given in Table 4 [9].

2.4.2. Thickness. Thickness of tablets was determined using Vernier Caliper (Indian caliper industries, Ambala, India). 
TABLE 5: Evaluation parameters for the optimization of Sodium Starch Glycolate.

\begin{tabular}{|c|c|c|c|c|c|c|c|}
\hline & Evaluation parameters & F1 (1\% SSG) & F2 (2\% SSG) & F3 (4\% SSG) & F4 (6\% SSG) & F5 (8\% SSG) & F6 (10\% SSG) \\
\hline 1 & Weight variation (IP) & Passed & Passed & Passed & Passed & Passed & Passed \\
\hline 2 & Friability (\%) & 0.8 & 0.8 & 0.1 & 0.3 & 0.1 & 0.1 \\
\hline 3 & ${ }^{*}$ Hardness $\left(\mathrm{Kg} / \mathrm{cm}^{2}\right) \pm \mathrm{SD}$ & $2.2 \pm 0.57$ & $1.6 \pm 0.28$ & $1.5 \pm 0.28$ & $1.5 \pm 0.32$ & $2.0 \pm 0.57$ & $1.8 \pm 0.28$ \\
\hline 4 & ${ }^{* *}$ Disintegration time $(\mathrm{Sec}) \pm \mathrm{SD}$ & $80 \pm 2.34$ & $59 \pm 6.67$ & $40 \pm 2.63$ & $48 \pm 6.38$ & $138 \pm 7.39$ & $95 \pm 6.97$ \\
\hline
\end{tabular}

* Average of three determinations, ${ }^{* *}$ average of six determinations.

Bold font refers to disintegration time of $4 \%$ SSG.

TABLE 6: Evaluation parameters for the optimization of Polyvinylpyrrolidone (PVP K-30) or Microcrystalline Cellulose as binder with optimized concentration of Sodium Starch Glycolate.

\begin{tabular}{|c|c|c|c|c|}
\hline \multirow{2}{*}{ Formula number } & \multicolumn{4}{|c|}{ Evaluation parameters } \\
\hline & Weight variation (IP) & Friability (\%) & ${ }^{*}$ Hardness $\left(\mathrm{Kg} / \mathrm{cm}^{2}\right) \pm \mathrm{SD}$ & ${ }^{* *}$ Disintegration time $(\mathrm{Sec}) \pm \mathrm{SD}$ \\
\hline $\mathrm{F} 1$ & Passed & 0.1 & $2.2 \pm 0.28$ & $60 \pm 1.78$ \\
\hline $\mathrm{F} 2$ & Passed & 0.2 & $1.8 \pm 0.28$ & $49 \pm 1.67$ \\
\hline F3 & Passed & 0.5 & $2.0 \pm 0.00$ & $69 \pm 2.89$ \\
\hline $\mathrm{F} 4$ & Passed & 0.3 & $3.2 \pm 0.76$ & $83 \pm 2.40$ \\
\hline F5 & Passed & 0.3 & $1.6 \pm 0.50$ & $90 \pm 5.16$ \\
\hline F6 & Passed & 0.8 & $2.5 \pm 0.50$ & $120 \pm 5.77$ \\
\hline F7 & Passed & 0.8 & $2.0 \pm 0.00$ & $145 \pm 5.43$ \\
\hline F8 & Passed & 0.1 & $1.5 \pm 0.50$ & $37 \pm 3.13$ \\
\hline F9 & Passed & 0.1 & $1.5 \pm 0.28$ & $47 \pm 1.34$ \\
\hline F10 & Passed & 0.2 & $1.5 \pm 0.28$ & $62 \pm 1.10$ \\
\hline F11 & Passed & 0.1 & $1.8 \pm 0.28$ & $75 \pm 1.32$ \\
\hline F12 & Passed & 0.1 & $1.5 \pm 0.28$ & $82 \pm 2.08$ \\
\hline $\mathrm{F} 13$ & Passed & 0.1 & $1.8 \pm 0.28$ & $96 \pm 1.84$ \\
\hline F14 & Passed & 0.1 & $1.8 \pm 0.28$ & $105 \pm 2.73$ \\
\hline
\end{tabular}

${ }^{*}$ Average of three determinations, ${ }^{* *}$ average of six determinations.

Bold font refers to disintegration time of 2\% PVP K-30 and disintegration time of $1 \%$ MCC.

TABLE 7: Evaluation parameters for Cetirizine Hydrochloride FDT.

\begin{tabular}{lcc}
\hline Sr. number & Evaluation parameters & Results \\
\hline 1 & Weight variation (IP) & Passed \\
2 & ${ }^{*}$ Thickness $(\mathrm{mm}) \pm \mathrm{SD}$ & $3.65 \pm 0.09$ \\
3 & ${ }^{*}$ Hardness $\left(\mathrm{Kg} / \mathrm{cm}^{2}\right) \pm \mathrm{SD}$ & $1.5 \pm 0.58$ \\
4 & Friability $(\%)$ & 0.5 \\
5 & ${ }^{* *}$ Disintegration time $(\mathrm{sec}) \pm \mathrm{SD}$ & $35 \pm 4.02$ \\
6 & ${ }^{*}$ Wetting time $(\mathrm{sec}) \pm \mathrm{SD}$ & $23 \pm 1.15$ \\
7 & ${ }^{*}$ Drug content uniformity $\pm \mathrm{SD}$ & $93.33 \pm 1.53$ \\
\hline
\end{tabular}

${ }^{*}$ Average of three determinations, ${ }^{* *}$ average of six determinations.

Three tablets from each batch were used and an average value was calculated [9].

2.4.3. Hardness. The crushing strength of the tablets was measured using a Monsanto Hardness Tester (Perfit). Three tablets from each formulation batch were tested randomly and the average reading was noted. The hardness is measured in $\mathrm{kg} / \mathrm{cm}^{2}[11]$.

2.4.4. Friability. Ten tablets were weighed and placed in a Roche Friabilator (Veego, India) and the equipment was rotated at $25 \mathrm{rpm}$ for $4 \mathrm{~min}$. The tablets were taken out, dedusted and reweighed. The percentage friability of the tablets was measured as per the following formula [12]

$$
\text { Percentage friability }=\frac{\text { Initial weight }- \text { Final weight }}{\text { Initial weight }} \times 100 \text {. }
$$

2.4.5. In-Vitro Disintegration Test. The test was carried out on 6 tablets using Digital Tablet Disintegration Tester (Veego, India). Distilled water at $37^{\circ} \mathrm{C} \pm 2^{\circ} \mathrm{C}$ was used as a disintegration media and the time in second taken for complete disintegration of the tablet with no palable massremaining in the apparatus was measured in seconds [13].

2.4.6. Wetting Time. A petridish containing $6 \mathrm{~mL}$ of distilled water was taken. A tablet containing a small quantity of amaranth color was placed on this. Time required for the upper surface of the tablet to become complete red was noted [14].

2.4.7. Drug Content Uniformity. Ten tablets $(200 \mathrm{mg})$ were powdered in mortar pestle and the blend equivalent to $5 \mathrm{mg}$ of Cetirizine Hydrochloride was weighed and dissolved in 
TABLE 8: Accelerated stability studies of Cetirizine Hydrochloride FDT stored at $40 \pm 2^{\circ} \mathrm{C} / 75 \% \mathrm{RH} \pm 5 \%$.

\begin{tabular}{|c|c|c|c|c|c|c|c|c|c|}
\hline \multirow{3}{*}{$\begin{array}{l}\text { Time interval } \\
\text { Evaluation parameters }\end{array}$} & \multicolumn{9}{|c|}{ Three primary batches } \\
\hline & \multicolumn{3}{|c|}{ Day 0} & \multicolumn{3}{|c|}{ The 15 th day } & \multicolumn{3}{|c|}{ The 30th day } \\
\hline & B-1 & B-2 & B-3 & B-1 & B-2 & B-3 & B-1 & B-2 & B-3 \\
\hline $\begin{array}{l}{ }^{*} \text { Hardness } \\
\left(\mathrm{Kg} / \mathrm{cm}^{2}\right) \pm \mathrm{SD}\end{array}$ & $1.3 \pm 0.58$ & $1.2 \pm 0.29$ & $1.8 \pm 0.29$ & $1.9 \pm 0.29$ & $2.0 \pm 0.29$ & $1.5 \pm 0.00$ & $3.0 \pm 0.5$ & $2.5 \pm 0.29$ & $1.7 \pm 0.29$ \\
\hline Friability (\%) & 0.1 & 0.4 & 0.6 & 0.3 & 0.4 & 0.2 & 0.1 & 0.2 & 0.5 \\
\hline Drug content \pm SD & $100.8 \pm 3.36$ & $95.6 \pm 2.34$ & $93.8 \pm 1.24$ & $98.5 \pm 2.14$ & $99.4 \pm 2.67$ & $90.42 \pm 3.64$ & $92.8 \pm 1.98$ & $99 \pm 1.65$ & $97.6 \pm 3.63$ \\
\hline $\begin{array}{l}{ }^{* *} \text { Disintegration } \\
\text { time }(\mathrm{sec}) \pm \mathrm{SD}\end{array}$ & $37 \pm 4.79$ & $40 \pm 3.64$ & $35 \pm 2.27$ & $44 \pm 2.06$ & $46 \pm 2.18$ & $39 \pm 3.09$ & $45 \pm 3.43$ & $50 \pm 3.27$ & $44 \pm 2.23$ \\
\hline
\end{tabular}

${ }^{*}$ Average of three determinations/batch. ${ }^{* *}$ average of six determinations/batch.

TABLE 9: Accelerated stability studies of Cetirizine Hydrochloride FDT at room temperature at ambient humidity.

\begin{tabular}{|c|c|c|c|c|c|c|c|c|c|}
\hline \multirow{3}{*}{$\begin{array}{l}\text { Time interval } \\
\text { Evaluation } \\
\text { parameters }\end{array}$} & \multicolumn{9}{|c|}{ Three primary batches } \\
\hline & \multicolumn{3}{|c|}{ Day 0} & \multicolumn{3}{|c|}{ The 15th day } & \multicolumn{3}{|c|}{ The 30th day } \\
\hline & B-1 & B-2 & B-3 & B-1 & B-2 & B-3 & B-1 & B-2 & B-3 \\
\hline $\begin{array}{l}\text { *Hardness } \\
\left(\mathrm{Kg} / \mathrm{cm}^{2}\right) \pm \mathrm{SD}\end{array}$ & $1.3 \pm 0.58$ & $1.2 \pm 0.29$ & $1.8 \pm 0.29$ & $1.4 \pm 0.50$ & $1.5 \pm 0.00$ & $1.7 \pm 0.29$ & $1.3 \pm 0.5$ & $1.5 \pm 0.29$ & $1.5 \pm 0.29$ \\
\hline Friability (\%) & 0.1 & 0.4 & 0.6 & 0.3 & 0.2 & 0.2 & 0.4 & 0.2 & 0.3 \\
\hline${ }^{*}$ Drug content $\pm \mathrm{SD}$ & $100.8 \pm 3.36$ & $95.6 \pm 2.34$ & $93.8 \pm 1.24$ & $99.5 \pm 2.14$ & $94.5 \pm 2.67$ & $94.8 \pm 1.23$ & $98.3 \pm 1.98$ & $95.4 \pm 1.65$ & $95.7 \pm 3.63$ \\
\hline $\begin{array}{l}{ }^{* *} \text { Disintegration } \\
\text { time }(\mathrm{sec}) \pm S D\end{array}$ & $37 \pm 4.79$ & $40 \pm 3.64$ & $35 \pm 2.27$ & $35 \pm 3.60$ & $42 \pm 4.44$ & $38 \pm 2.18$ & $40 \pm 3.64$ & $38 \pm 1.05$ & $41 \pm 1.31$ \\
\hline
\end{tabular}

${ }^{*}$ Average of three determinations/batch, ${ }^{* *}$ average of six determinations/batch.

$100 \mathrm{~mL}$ of $6.8 \mathrm{pH}$ phosphate buffer solutions. The solution was sonicated, filtered through whatman filter paper, suitably diluted with $6.8 \mathrm{pH}$ phosphate buffer and the drug content was analyzed by using Double Beam UV Spectrophotometer (UV-1800 Shimadzu) at $230 \mathrm{~nm}$ respectively. Each sample was analyzed in triplicate.

2.4.8. In Vitro Dissolution Study. The release of from formulated FDTs was determined using USP eight stage dissolution testing apparatus-2 (paddle method) (Lab, India). The dissolution test was performed using $500 \mathrm{~mL}$ of phosphate buffer solution, $\mathrm{pH} 6.8$ at $37 \pm 0.5^{\circ} \mathrm{C}$ and $50 \mathrm{rpm}$. A sample $(5 \mathrm{~mL})$ of the solution was withdrawn from the dissolution apparatus at specific time intervals and the samples were replaced with fresh dissolution medium. The samples were filtered through Whatman filter paper. Absorbance of these solutions was measured at $230 \mathrm{~nm}$ using a Double Beam UV Spectrophotometer (UV-1800 Shimadzu). Cumulative percentage (\%) of drug release was calculated using standard plot of Cetirizine Hydrochloride [15].

2.4.9. Drug-Excipient Compatibility Studies. These studies were performed in order to confirm the drug-excipient interaction. These studies mainly include FTIR Spectroscopy. FTIR spectra of pure drugs and formulated FDT containing drug were recorded on FTIR Spectrophotometer (Bruker, USA). The scanning range was from 4000 to $600 \mathrm{~cm}^{-1}$ and the resolution was $1 \mathrm{~cm}^{-1}$. The scans were evaluated for presence of principal peaks of drug, shifting and masking of drug peaks, and appearance of new peaks due to excipient interaction. This spectral analysis was employed to check the compatibility of drugs with the excipients used [16].

2.4.10. Accelerated Stability Studies. The selected formulations were closely packed in aluminum foils and then stored at $40 \pm 2^{\circ} \mathrm{C} / 75 \% \mathrm{RH} \pm 5 \%$ in stability chamber for 1 month and evaluated for their physical appearance, drug content, percent friability, and in vitro disintegration time at intervals of the 15th and 30th days [17].

\section{Results and Discussion}

The present investigation was undertaken to formulate and evaluate fast disintegrating tablets of Cetirizine Hydrochloride by direct compression method using Sodium Starch Glycolate as a superdisintegrant and Mannitol as directly compressible diluent and Sodium Saccharin was used to enhance palatability. Avicel PH 102 was included in the formulation as a disintegrant and a binder. This grade of Microcrystalline Cellulose is granular in nature and thus displays excellent flow properties. To impart pleasant taste and improve mouth feel, Sodium Saccharin was included as sweetening agent. Sodium Stearyl Fumarate was employed as a lubricant instead of Magnesium Stearate not only because of the metallic taste of the latter, but also due to its water solubility and directly compressible features.

3.1. Optimization of Superdisintegrant Sodium Starch Glycolate (Primogel, Explotab). Superdisintegrants are generally used by formulation scientists for developing FDTs or for 
improvement of solubility for drugs. The primary requirement for such dosage forms is quicker disintegration. The amount of superdisintegrants was optimized in the formulation of FDTs. The total 6 formulations (F1-F6) were prepared using different concentration of Sodium Starch Glycolate to study its effect on disintegration time. The results for optimization of superdisintegrant concentration in FDTs by direct compression method are shown in Table 5.

From the evaluation parameters, it was observed that 4\% Sodium Starch Glycolate was the optimum concentration for rapid tablet disintegration on the basis of the least disintegration time observed with F3 formulation. The superdisintegrant action of Sodium Starch Glycolate resulted in hydrophilicity and swelling which in turn causes rapid disintegration. It absorbs water rapidly and swells in water to the extent of $200-300 \%$ and disintegrates rapidly. Sodium Starch Glycolate is used as superdisintegrant in tablet formulation at a concentration of $4-6 \%$. Above $8 \%$ disintegration times may actually increase due to gelling and its subsequent viscosity producing effects.

3.2. Optimization of Polyvinylpyrrolidone (PVP K-30) or Microcrystalline Cellulose (Avicel PH-102) as Binder along with Optimized Concentration of Superdisintegrant. The binders such as Polyvinylpyrrolidone (PVP K-30) or Microcrystalline Cellulose were optimized with superdisintegrant concentration to further study the effect of binders on the disintegration time as well as on hardness and friability of tablets of the formulation. Total 14 formulations (F1-F14) were prepared using different concentration of Polyvinylpyrrolidone (PVP K-30) or Microcrystalline Cellulose to study its effect on disintegration time of formulations. The results for optimization of different binder in FDTs by direct compression method are shown in Table 6.

From the evaluation parameters, it was observed that disintegration time of the formulation was further decreased and tablet hardness, friability with in IP limits. The least disintegration time was observed in F8 formulation, that is, $1 \%$ MCC, as compared to F2 formulation, that is, $2 \%$ PVP $\mathrm{K}-30$. Water soluble materials such as PVP K-30 tend to dissolve rather than disintegrate, while insoluble materials like MCC generally produce rapidly disintegrating tablets. Due to the presence of porous morphology, liquid is drawn up or "wicked" into these pathways through capillary action and ruptures the interparticulate bonds causing the tablet to break apart. Therefore 1\% Microcrystalline Cellulose was selected as optimum binder concentration selected for final formulation of Cetirizine Hydrochloride FDT.

3.3. Evaluation Parameters for Cetirizine Hydrochloride Fast Disintegrating Tablet. Final formulation of Cetirizine Hydrochloride FDT was tested for all the official tests of tablet and was found to be within limits as shown in Table 7. Percent weight variation was well within the acceptable limit for uncoated tablets as per Indian Pharmacopoeia. It is well known to formulation scientists that the tablets with more hardness show longer disintegration time. Since mechanical

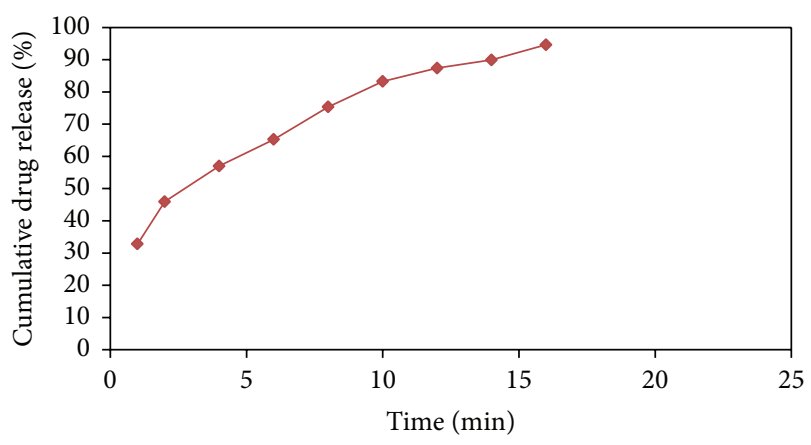

Figure 1: In-vitro Dissolution Profile of Cetirizine Hydrochloride FDT.

integrity is of paramount importance in successful formulation of FDTs, hence the hardness of tablets was determined. The friability of Cetirizine Hydrochloride FDT was less than $1 \%$ which is acceptable according IP criteria. The content uniformity of the prepared Cetirizine Hydrochloride FDT was complied with IP specifications. No tablet from ten tablets lies out of the range of $85-115 \%$ of the label claim. These results indicated that the dosage form had uniform distribution and proper dose of the active ingredient. The wetting time and disintegration time were practically good for formulation. According to IP, the dispersible tablet must disintegrate within 3 minutes, but the formulated FDTs showed low DT indicating suitability of formulation for mouth dissolving tablet.

3.4. In Vitro Dissolution Study. In vitro dissolution studies showed that more than $50 \%$ of the drug was released from the formulation within 5 minutes. The rapid drug dissolution might be due to easy breakdown of particle by superdisintegrant action. From in vitro dissolution data, it was observed that $94.74 \pm 2.48 \%$ of Cetirizine Hydrochloride released in 16 minutes as shown in Figure 1 indicates that the tablet complies as per IP specifications, that is, $85 \%-110 \%$.

3.5. Drug-Excipient Compatibility Studies. The results obtained with IR studies showed that there was no interaction between the drug and other excipients used in the formulation. The FTIR of Cetirizine Hydrochloride had shown intense band at $757.13 \mathrm{~cm}^{-1}, 1317.62 \mathrm{~cm}^{-1}, 1055.66 \mathrm{~cm}^{-1}$ and $1184.57 \mathrm{~cm}^{-1}$ corresponding to the presence of functional groups such as aliphatic chlorocompound, carboxylic acid, alkyl substituted ether and tertiary amine. The FTIR of Cetirizine Hydrochloride FDT formulation shown intense bands at $758.41 \mathrm{~cm}^{-1}, \quad 1312.37 \mathrm{~cm}^{-1}, \quad 1078.32 \mathrm{~cm}^{-1}$ and $1181.48 \mathrm{~cm}^{-1}$ indicates no change in the functional groups such as aliphatic chlorocompound, carboxylic acid, alkyl substituted ether, and tertiary amine confirming undisturbed structure of Cetirizine Hydrochloride, which indicates no drug-excipient interaction as shown in Figure 2.

3.6. Accelerated Stability Studies. In the present study, stability studies were carried out on formulated FDTs (formulated 

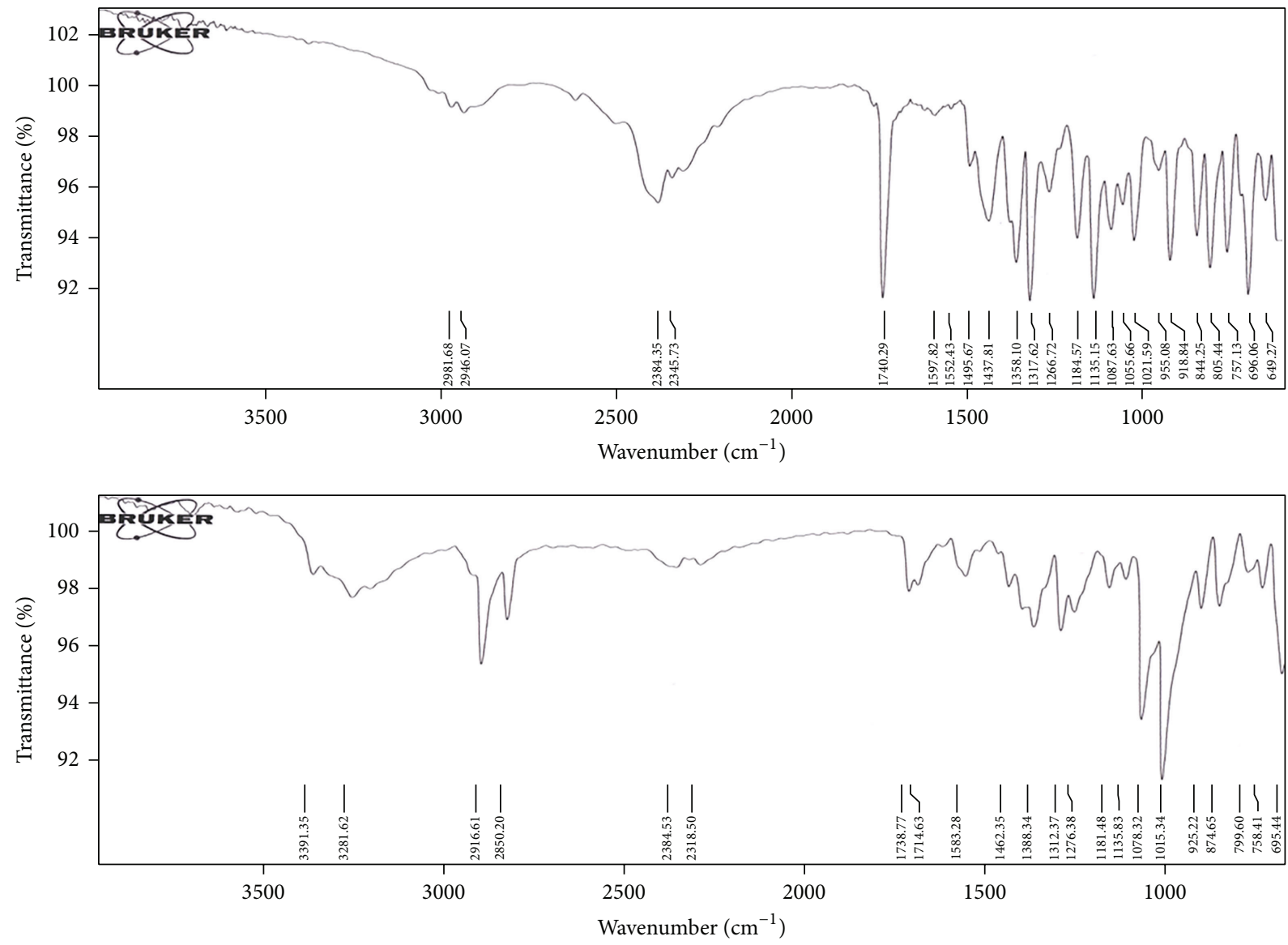

FIGURE 2: FTIR Spectra of Cetirizine Hydrochloride (Pure Drug) V/S FTIR Spectra of Cetirizine Hydrochloride FDT.

in three primary batches), wrapped in aluminium foil to prevent the formulation from exposure to light to simulate the aluminum packaging, that is, Alu Alu packing, of drug products, and stored in air-tight containers which is impermeable to solid, liquid, and gases, under the following condition for onemonth period as prescribed by ICH guidelines for accelerated stability study. During the stability studies, the product is exposed to normal condition of temperature and humidity. However the studies will take a longer time and hence it would be convenient to carry out accelerated stability studies, where the product is stored under extreme condition of temperature and humidity. The stability data of formulation are shown in Tables 8 and 9 as given.

Result is obtained after 1 month of stability studies at room temperature and at ambient humidity.

The result of the stability study indicated that there were not many differences observed in hardness, disintegration time, drug content uniformity, and friability before and after the storage period at room temperature and at ambient humidity, but, at temperature of $40 \pm 2{ }^{\circ} \mathrm{C} / 75 \% \mathrm{RH} \pm 5 \%$ relative humidity, hardness was increased with time, prolonging the DT of the tablet; the probable reason was loss of moisture from tablets, but, in all cases, DT is within the specified IP limit (within $3 \mathrm{~min}$ ). This indicates that formulation is fairly stable at both storage conditions.

\section{Conclusion}

Fast disintegrating tablet is a promising approach with a view of obtaining faster action of the drug and would be advantageous in comparison to currently available conventional dosage forms. The FDT dosage form had a good balance over disintegration time and mechanical strength. The prime objective of the study was to develop Cetirizine Hydrochloride fast disintegrating tablet by using commonly available excipients and conventional technology. From the above study, it was concluded that, by employing commonly available pharmaceutical excipients, such as superdisintegrants, hydrophilic and swellable excipients and proper filler, a fast disintegrating tablet of Cetirizine Hydrochloride can be developed which can be commercialized.

\section{Conflict of Interests}

The authors declare that they do not have any financial or personal relationships with other people or any other organizations that could inappropriately influence this research work.

\section{Acknowledgments}

The authors are highly acknowledge NB Entrepreneurs, Nagpur, and Trojan Pharma, Baddi, India, for providing gift 
samples of Avicel PH-102 and Cetirizine Hydrochloride, also Dr. Mahendra Singh Rathore for his valuable suggestions, and also CT Institute of Pharmaceutical Sciences, Jalandhar, for their efforts to facilitate the use of the necessary instruments and materials required during the entire course of this research work.

\section{References}

[1] J. Balasubramaniam, K. Bindu, V. U. Rao, D. Ray, R. Haldar, and A. W. Brzeczko, "Effect of superdisintegrants on dissolution of cationic drugs," Dissolution Technologies, vol. 15, no. 2, pp. 1825, 2008.

[2] S. Avulapati, A. K. Roy, K. R. Shashidhar, and T. Ugendarreddy, "Formulation and evaluation of taste masked and fast disintegrating Losartan Potassium tablets," International Journal of Drug Development and Research, vol. 3, no. 1, pp. 45-51, 2011.

[3] G. Y. Narmada, K. Mohini, B. P. Rao, D. X. P. Gowrinath, and K. S. Kumar, "Formulation, evaluation and optimization of fast dissolving tablets containing amlodipine besylate by sublimation method," Ars Pharmaceutica, vol. 50, no. 3, pp. 129144, 2009.

[4] D. Shukla, S. Chakraborty, S. Singh, and B. Mishra, "Mouth dissolving tablets II: an overview of evaluation techniques," Scientia Pharmaceutica, vol. 77, no. 2, pp. 327-341, 2009.

[5] S. Corveleyn and J. P. Remon, "Formulation and production of rapidly disintegrating tablets by lyophilisation using hydrochlorothiazide as a model drug," International Journal of Pharmaceutics, vol. 152, no. 2, pp. 215-225, 1997.

[6] A. K. Nayak and K. Manna, "Current developments in orally disintegrating tablet technology," Journal of Pharmaceutical Education and Research, vol. 2, no. 1, pp. 21-34, 2011.

[7] S. A. Sreenivas, P. M. Dandagi, A. P. Gadad et al., "Orodispersible tablet: new-fanged drug delivery system-a review," Indian Journal of Pharmaceutical Education and Research, vol. 39, no. 4, pp. 177-181, 2005.

[8] D. Bhowmik, B. Chiranjib, Krishnakanth, Pankaj, and R. M. Chandira, "Fast dissolving tablet: an overview," Journal of Chemical and Pharmaceutical Research, vol. 1, no. 1, pp. 163-177, 2009.

[9] S. B. Jadhav, D. R. Kaudewar, G. S. Kaminwar, A. B. Jadhav, R. V. Kshirsagar, and D. M. Sakarkar, "Formulation and evaluation of dispersible tablets of diltiazem hydrochloride," International Journal of PharmTech Research, vol. 3, no. 3, pp. 1314-1321, 2011.

[10] K. D. Tripathi, Essential of Medical Pharmacology, Jaypee Brothers Medical Publisher, New Delhi, India, 6th edition, 2008.

[11] M. Vishal, K. Anuj, P. Naveen, P. Kumud, and S. Sangram, "Formulation and evaluation of orodispersible tablets of lornoxicam," International Journal of Drug Development and Research, vol. 3, no. 1, pp. 281-285, 2011.

[12] A. Arya, S. Sharma, J. Kumar, A. Chandra, and P. Jaiswal, "Formulation and evaluation of mouth dissolving tablets of ranitidine HCL," International Journal of PharmTech Research, vol. 2, no. 2, pp. 1574-1577, 2010.

[13] R. B. Parmar, A. H. Baria, H. M. Tank, and S. D. Faldu, "Formulation and evaluation of domperidone fast dissolving tablets," International Journal of PharmTech Research, vol. 1, no. 3, pp. 483-487, 2009.

[14] B. Senthilnathan and A. Rupenagunta, "Formulation development and evaluation of venlafaxine hydrochloride orodispersible tablets," International Journal of Pharmaceutical Sciences and Research, vol. 2, no. 4, pp. 913-921, 2011.
[15] P. B. Anjankumar, M. Nazmuddin, U. Kulkarni, and R. C. Hariprasanna, "Formulation and evaluation of lornoxicam fast dissolving tablet," International Research Journal of Pharmacy, vol. 2, no. 4, pp. 130-133, 2011.

[16] N. C. Mohire and A. V. Yadav, "Novel approach to formulate $\beta$ cyclodextrin complexed mouth dissolving tablet of metronidazole and its in-vitro evaluation," Journal of Pharmacy Research, vol. 3, no. 3, pp. 662-667, 2010.

[17] "ICH Harmonised Tripartite Guideline," Cover Note for Revision of Q1A(R) Stability Testing of New Drug Substances and Products, Q1A (R2). 

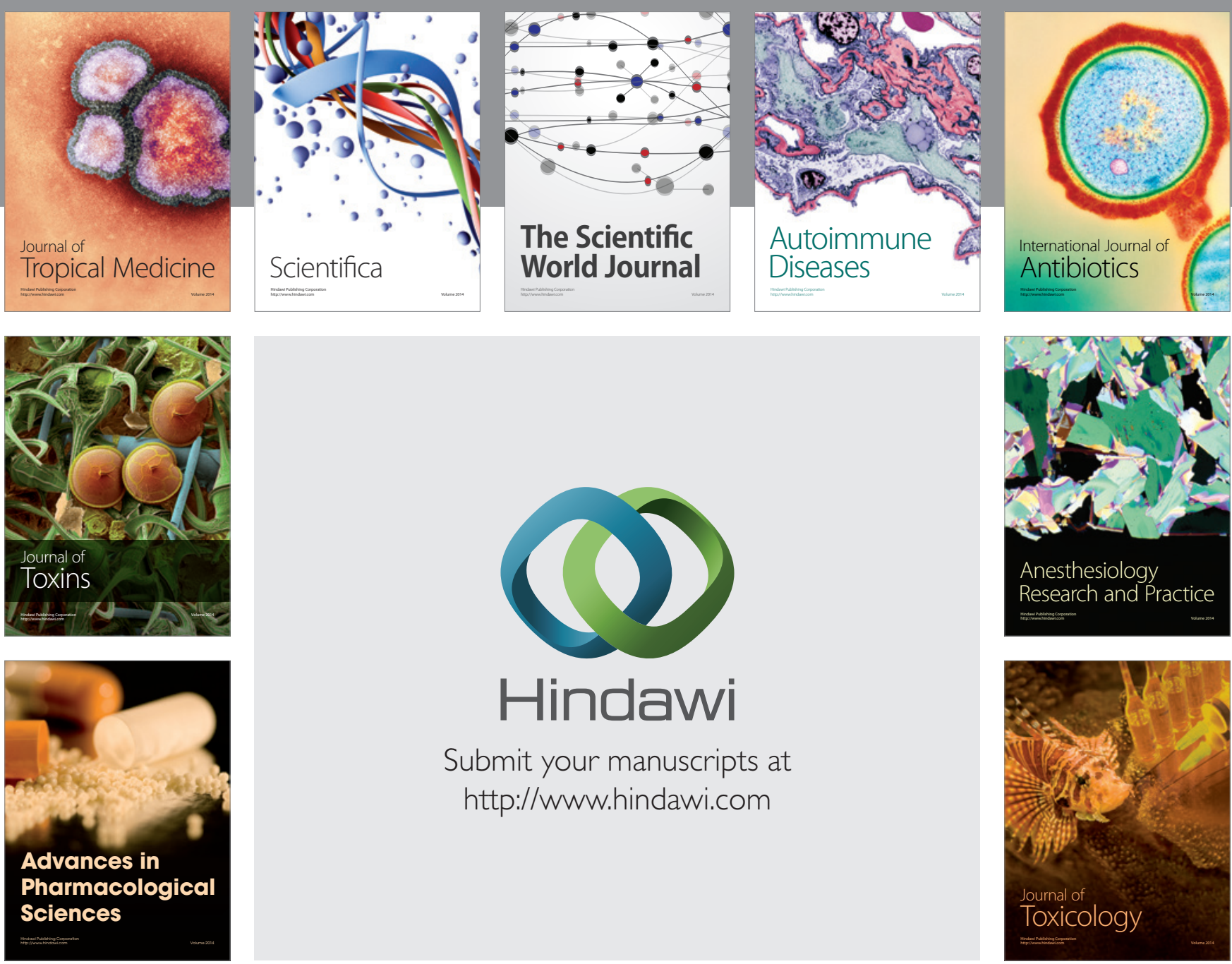

\section{Hindawi}

Submit your manuscripts at

http://www.hindawi.com
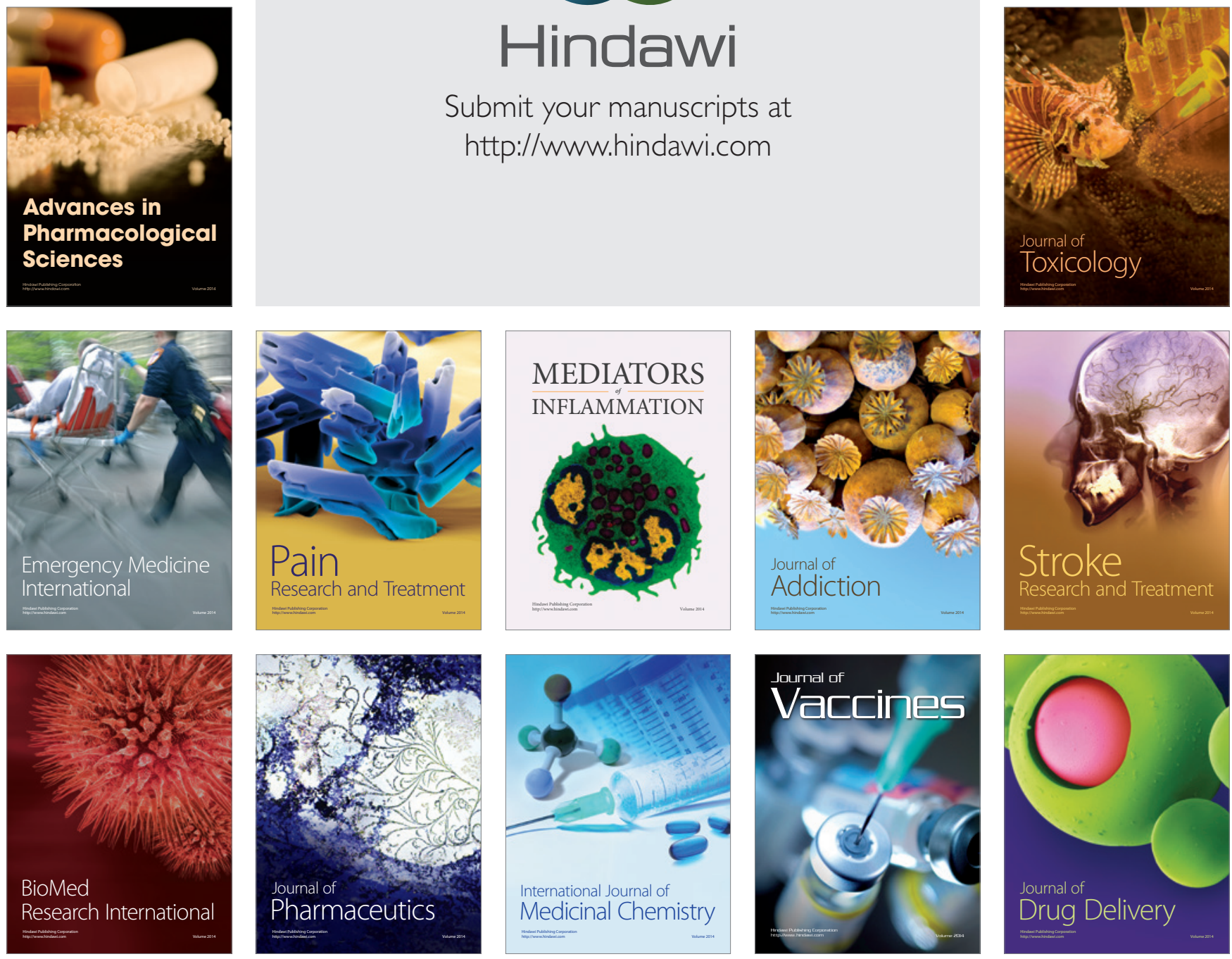